HortSCIENCE 26(4):377-380. 1991.

\title{
Shoot Growth and Gross Photosynthesis of Evergreen Azaleas
}

\author{
David J. Ballantyne \\ Department of Biology, University of Victoria, Victoria, B.C. V8W 2Y2, \\ Canada \\ Additional index words, gibberellic acid, photosynthetic photon flux density, \\ Rhododendron
}

\begin{abstract}
The influence of photosynthetic photon flux density (PPFD) and gibberellic acid $\left(\mathbf{G A}_{3}\right)$ sprays on shoot elongation was determined for 'Coral Bells' (Kurume or $\boldsymbol{R}$. obstusum hybrid), 'Fashion' (Glen Dale or $R$. indicum $\times$ Kurume hybrid), 'Hexe' ( $R$. obtusum $\times R$. simsii hybrid), 'Hinocrimson' (Kurume or $R$. obtusum hybrid), 'Hinodegiri' (Kurume or $R$. obtusum hybrid), and 'Red Wing' (Brooks hybrid) azalea. GA at $1 \mathrm{~mm}$ was more effective in stimulating shoot elongation of 'Coral Bells', 'Fashion', 'Hinodegiri', and 'Red Wing' than of 'Hexe' or 'Hinocrimson'. GA 3 sprays were more effective in stimulating elongation when applied to plants growing at irradiance levels of $350 \mu \mathrm{mol} \cdot \mathrm{s}^{-1} \cdot \mathrm{m}^{-2}$ than to plants growing at either 200 or $100 \mu \mathrm{mol} \cdot \mathrm{s}^{-1} \cdot \mathrm{m}^{-2}$. Gross photosynthesis of leaf segments was higher for a slow-growing cultivar (Hinocrimson) than for a faster-growing cultivar (Fashion). 'Hinocrimson' produced stouter shoots (greater dry weight/cm) than did 'Fashion'.
\end{abstract}

The time required for shoot elongation of evergreen azaleas (Rhododendron CVs) is

Received for publication 21 Nov. 1988. I acknowledge support from the Faculty Research Fund of the Univ. of Victoria. The cost of publishing this paper was defrayed in part by the payment of page charges. Under postal regulations, this paper therefore must be hereby marked advertisement solely to indicate this fact. considerably longer than for other stages of production (Batson, 1975). Faster shoot elongation should lead to a decreased time between prunings and a shorter production time. Gibberellic acid $\left(\mathrm{GA}_{3}\right)$ has stimulated shoot elongation of azalea seedlings (Sink and Walker, 1964). Greenhouse azaleas of the Belgian indica group that have a high rate of photosynthesis when grown at high photosynthetic photon flux density (PPFD), also 


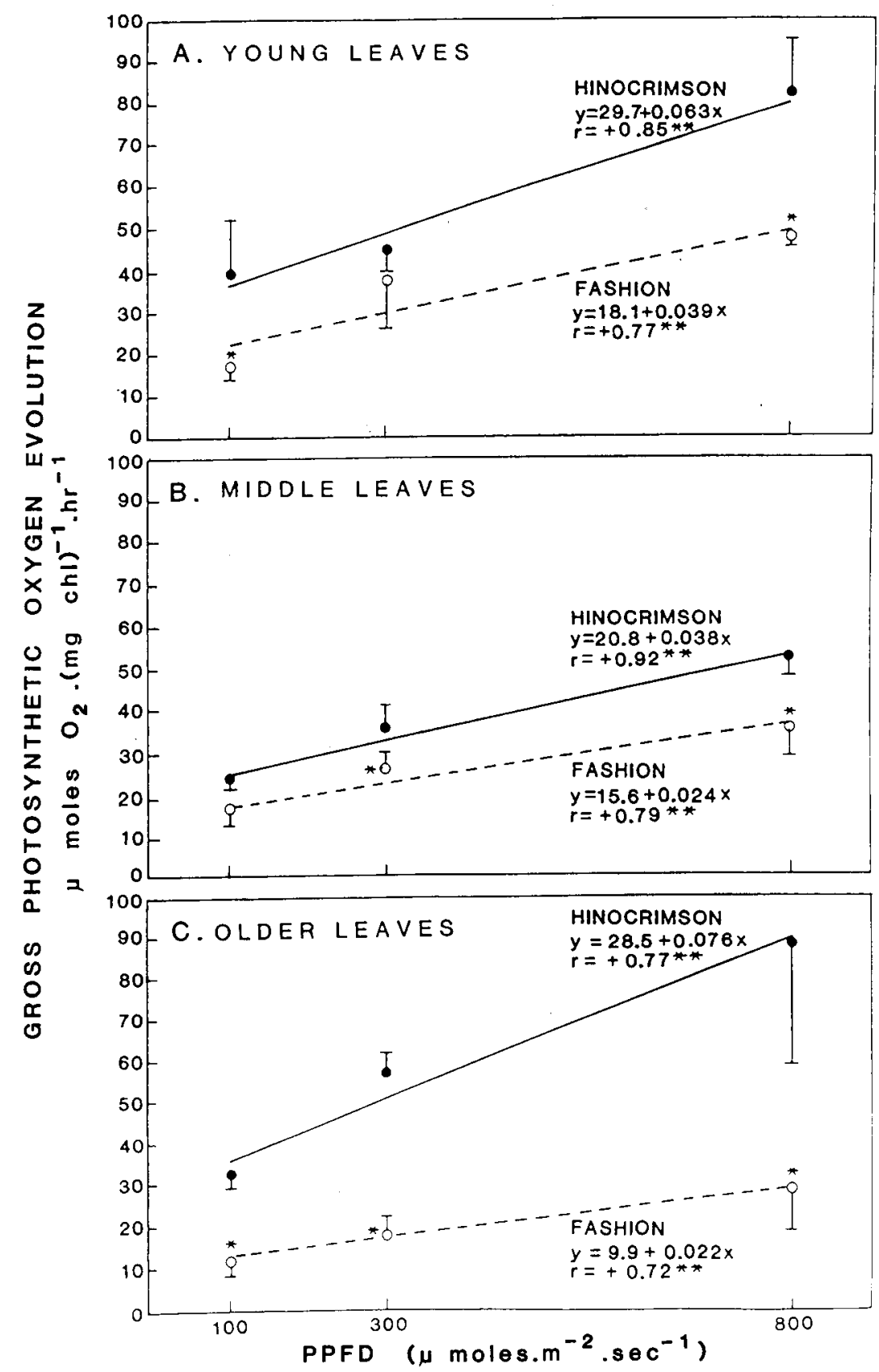

Fig. 1. Influence of PPFD and leaf age on gross photosynthesis of leaf segments of 'Fashion' and 'Hinocrimson' azaleas. (A) Young leaves: youngest fully expanded leaves on 7-week-old shoots. (B) Middle leaves: second oldest leaves on 10-week-old shoots. (C) Older leaves: top, fully expanded leaves on 8-month-old shoots pruned 4 weeks before leaf removal. Means are of four replicates. Vertical bars represent standard errors of the means. **Indicates correlation coefficients that are significant at $P=0.01$. *Above a mean for 'Fashion' indicates that it is significantly different from the respective 'Hinocrimson' mean at $P=0.05$.

have a high rate of shoot elongation, and a correlation between shoot growth and photosynthesis of cultivars was indicated (Ceulemans et al., 1984).

The purpose of these studies was to determine the influence of PPFD and GA on shoot elongation of evergreen azalea cultivars hardy in southwestern British Columbia, and to investigate the relationship between gross photosynthesis and shoot elongation of these cultivars.

One-year-old plants were dug in the field and potted into 15 -cm-diameter (1.41-liter) azalea pots with 1 peat $: 1$ sand (v/v) in June
2 weeks before the plants were placed in growth chambers, when axillary shoots could only be detected with a binocular microscope. Growth and photosynthetic relationships between cultivars did not depend on time of digging or time of year in which the plants were held in the greenhouse. In growth chambers, the photoperiod was $15 \mathrm{~h}$, days were at $22.7 \pm 0.3 \mathrm{C}$ and nights at $13.5 \pm$ $0.2 \mathrm{C}$ (an attempt to approximate late spring and summer temperatures in southwestern British Columbia). Light sources were coolwhite fluorescent tubes providing $89 \%$ of the irradiation and incandescent bulbs providing $11 \%$ of the irradiation. Growth chamber PPFDs were 100, 200, and 350 $\mu \mathrm{mol} \cdot \mathrm{s}^{-1} \cdot \mathrm{m}^{-2}$. Where $\mathrm{GA}_{3}(1 \mathrm{~mm}$ in $0.1 \%$ Tween 20) was applied, five weekly sprays were used. Controls contained $0.1 \%$ Tween 20. Plants were sprayed to runoff. Sprays began 2 weeks after plants were placed in the growth chambers. $\mathrm{GA}_{3}$ at $1 \mathrm{~mm}$ was considered to be a concentration sufficient to stimulate shoot growth at a cost low enough to have commercial potential. Shoots were measured after plants had been in the growth chambers for 8 weeks.

A second shoot growth experiment involving 'Fashion' and 'Hinocrimson' was carried out in 1987. Plants were dug in the field in August, potted and pruned and placed in the greenhouse for 2 weeks, and then placed in a growth chamber at $250 \mu \mathrm{mol} \cdot \mathrm{s}^{-1} \cdot \mathrm{m}^{-2}$ for 6 weeks, a photoperiod of $15 \mathrm{~h}$, days at $22.7 \pm 0.3 \mathrm{C}$ and nights at $13.5 \pm 0.2 \mathrm{C}$. Then the plants were returned to the $16 \pm$ 1C (night temperature) greenhouse and shoot elongation and dry weight were determined after plants had been in the greenhouse for 7 weeks.

Gross photosynthesis of leaf segments was measured with the Clark $\mathrm{O}_{2}$ electrode (Steffen and Palta, 1986) that rapidly determines the oxygen flux of irradiated tissues (Badger, 1985). Five leaf disks were cut from leaves on shoots of 'Hinocrimson' and 'Fashion' plants growing at $300 \mu \mathrm{mol} \cdot \mathrm{s}^{-1} \cdot \mathrm{m}^{-2}$ under a 15 -h photoperiod, days at $22.7 \pm 0.3 \mathrm{C}$ and nights at $13.5 \pm 0.2 \mathrm{C}$. Leaves were selected from three positions on the shoots. Young leaves were the youngest fully expanded leaves on 7-week-old shoots; middle leaves were the second oldest leaves on 10week-old shoots; and older leaves were the top fully expanded leaves on 8-month-old shoots that were pruned 4 weeks before leaf removal. Five leaf disks, $4 \mathrm{~mm}$ in diameter, were cut from each of two leaves (10 disks total). Each of the leaf disks was cut in half and 20 leaf segments were placed in $3 \mathrm{ml} 50$ mM HEPES and $0.5 \mathrm{~mm} \mathrm{CaSO}_{4}$ (Steffen and Palta, 1986). The leaf segments were vacuum infiltrated twice (to avoid excessive bubbling) for $3 \mathrm{~min}$ with a water aspirator that achieved a vacuum of $722 \mathrm{~mm} \mathrm{Hg}$, measured with a Marsh Mastergauge (Marsh Instrument Co., Mississauga, Ont.). Leaf segments were given a 10-min pre-illumination of $500 \mu \mathrm{mol} \cdot \mathrm{s}^{-1} \cdot \mathrm{m}^{-2}$; in preliminary experiments there was little difference between this pre-illumination PPFD and a preillumination PPFD identical to the reaction 
Table 1. Influence of cultivar, irradiance during growth (PPFD), and GA3on azalea elongation.

\begin{tabular}{|c|c|c|c|c|c|}
\hline \multirow[b]{3}{*}{ Cultivar } & \multirow[b]{3}{*}{$\mathrm{GA}_{3}$} & & \multicolumn{3}{|c|}{ Shoot elongation over 8 weeks $(\mathrm{cm})$} \\
\hline & & & \multicolumn{3}{|c|}{ Photosynthetic photon flux density $\left(\mu \mathrm{mol} \cdot \mathrm{s}^{-1} \cdot \mathrm{m}^{2}\right)$} \\
\hline & & & 100 & 200 & 350 \\
\hline \multirow[t]{2}{*}{ Coral Bells } & - & & $5.1^{2}$ & 4.3 & 4.1 \\
\hline & + & & 7.8 & 7.0 & 9.3 \\
\hline \multirow[t]{2}{*}{ Fashion } & - & & 7.1 & 6.3 & 5.3 \\
\hline & + & & 9.2 & 8.4 & 10.8 \\
\hline \multirow[t]{2}{*}{ Hexe } & - & & 5.9 & 5.0 & 4.8 \\
\hline & + & & 6.4 & 6.3 & 6.2 \\
\hline \multirow[t]{2}{*}{ Hinocrimson } & - & & 5.4 & 4.2 & 4.5 \\
\hline & + & & 6.0 & 6.3 & 6.4 \\
\hline \multirow[t]{2}{*}{ Hinodegiri } & - & & 4.5 & 4.0 & 5.0 \\
\hline & + & & 7.8 & 7.6 & 7.6 \\
\hline \multirow[t]{2}{*}{ Red Wing } & - & & 5.9 & 4.7 & 3.6 \\
\hline & + & & 8.4 & 7.0 & 7.8 \\
\hline \multicolumn{6}{|l|}{ ANOVA } \\
\hline \multicolumn{2}{|l|}{ PPFD } & $* *$ & & & \\
\hline \multicolumn{2}{|l|}{ Gibberellin } & $* * *$ & & & . \\
\hline \multicolumn{2}{|c|}{ Cultivar } & **** & & & \\
\hline \multicolumn{2}{|c|}{ PPFD $\times$ gibberellin } & $* *$ & & & \\
\hline \multicolumn{2}{|c|}{ Gibberellin $\times$ cultivar } & ** & & & \\
\hline \multicolumn{2}{|c|}{ PPFD $\times$ cultivar } & NS & & & \\
\hline \multicolumn{2}{|c|}{ PPFD $\times$ gibberellin $\times$ cultivar } & NS & & & \\
\hline \multicolumn{2}{|c|}{$\mathrm{LSD}_{0.05}$} & 1.53 & & & \\
\hline
\end{tabular}

${ }^{\mathrm{z}}$ Mean of five replicates.

Nonsignificant or significant at $P=0.01$ or 0.001 , respectively.

PPFD. Following pre-illumination, $0.1 \mathrm{ml}$ $\mathrm{NaHCO}_{3}$ (final concentration $12.4 \mathrm{~mm}$ ) was added and $\mathrm{O}_{2}$ evolution was determined with a YSI Model 53 Clark oxygen electrode (YSI, Silver Spring, Md.) at the PPFD indicated and $30 \mathrm{C}$ (employed becaused it was found to be optimal for gross photosynthesis of azalea leaf segments). This temperature has been found to be optimal for spinach chloroplast activity (McEvoy and Lynn, 1972) and pea leaf gross photosynthesis (Hellmuth, 1971). The reaction PPFDs were 100, 300, and $800 \mu \mathrm{mol} \cdot \mathrm{s}^{-1} \cdot \mathrm{m}^{-2}$. Shoot elongation had been determined at the lowest reaction PPFD in the growth chamber, and the rate of gross photosynthesis at $800 \mu \mathrm{mol} \cdot \mathrm{s}^{-1} \cdot \mathrm{m}^{-2}$ was the same as that measured at $2000 \mu \mathrm{mol} \cdot \mathrm{s}^{-1} \cdot \mathrm{m}^{-2}$ (assumed as saturating).

Chlorophyll concentrations of the leaf segments were obtained using $96 \%$ ethanol (Wintermans and DeMots, 1965).

Determinations of shoot elongation of the new shoots that emerged following pruning were made from five plants per treatment. Gross photosynthesis determinations were replicated four times, each replicate from a separate plant. Analysis of variance followed by determinations of the least significant difference were carried out on shoot elongation data. Regressions were computed according to Li (1964) on gross photosynthesis data. Differences between means were tested at $P$ $=0.05$.

$\mathrm{GA}_{3}$ was most effective in stimulating shoot elongation when applied to plants receiving $350 \mu \mathrm{mol} \cdot \mathrm{s}^{-1} \cdot \mathrm{m}^{-2}$ (Table 1). Also, $\mathrm{GA}_{3}$ was more effective in stimulating shoot elongation in 'Coral Bells', 'Fashion', 'Hinodegiri' and 'Red Wing' than in 'Hexe' or 'Hinocrimson'. The rate of shoot elongation of 'Fashion' was greater than that of the other cultivars. The $\mathrm{GA}_{3}$ treatment stimulated shoot elongation in all cultivars but not at all PPFDs. Except for 'Hexe' and 'Hinocrimson', $\mathrm{GA}_{3}$ flower bud dormancy at a high light intensity (Furuta and Straiton, 1966). Perhaps photosynthesis is required for $\mathrm{GA}_{3}$ action or its translocation.

While $\mathrm{GA}_{3}$ treatments may permit more frequent prunings, they often result in a decrease of frost hardiness (Levitt, 1980). Thus, $\mathrm{GA}_{3}$-treated plants growing outside may be more susceptible to freezing injury and may be more suitably grown in a greenhouse.

In 'Fashion' and 'Hinocrimson' azalea, elongation was not related to photosynthesis. However, 'Hinocrimson' is a Kurume or $R$. obtusum hybrid and 'Fashion' is a Glenn Dale or $R$. indicum $\times$ Kurume hybrid (Galle, 1985); thus, the two cultivars are not closely related. However, in the study carried out by Ceulemans et al. (1984), the slower-growing and photosynthesizing 'Apollo' was a parent of the faster-growing and photosynthesizing 'Knut Erwen' (Heursel, 1985), both being Belgian indica cultivars. In this study, there was no difference in the dark respiration rate between 'Fashion' and 'Hinocrimson', and the rate of photosynthesis would seem to account for observed differences in oxygen flux. Photosynthesis should be a satisfactory means of predicting shoot elongation of hybrids produced from closely related cultivars, especially in the Belgian indica group, but gross photosynthesis may not be used to predict shoot elongation in other hybrids. Gross photosynthesis may be used to predict dry weight $/ \mathrm{cm}$ of shoots, but shoot dry weight and shoot elongation are not always closely related. Many factors other than photosynthesis rate may determine shoot elongation, including translocation of photosynthate and endogenous phytohormone levels.

\section{Literature Cited}

Badger, M.R. 1985. Photosynthetic oxygen exchange. Annu. Rev. Plant Physiol. 36:27-53.

Batson, F. 1975. Azalea, p. 194-213. In: V. Ball (ed.). Ball red book. Gee. J. Ball, Inc. W. Chicago.

Ceulemans, R.J. Heursel, N. Ibrahim, and L Impens. 1984. Variations among physiological, morphological and biochemical characteristics of evergreen azalea (Rhododendron simsii Planch.) cultivars. Scientia Hort. 22:147-155.

Furuta, T. and T.H. Straiton. 1966. Synergism of kinetin and gibberellic acid in flowering of unchilled azalea cultivar Red Wing. Proc. Amer. Hort. Sci. 88:591-594.

Galle, F.C. 1985. Azaleas. Timber Press, Portland, Ore.

Hellmuth, E.O. 1971. The effect of varying air$\mathrm{CO}_{2}$ levels, leaf temperature, and illuminance on the $\mathrm{CO}_{2}$ exchange of the dwarf pea Pisum sativum L. var. Meteor. Photosynthetic 5:190194.

Heursel, J. 1985. Description of Belgian evergreen Indian hybrids grown in western Europe, p. 137-153. In: F.C. Galle (ed.). Azaleas. Timber Press, Portland, Ore.

Levitt, J. 1980. Responses of plants to environmental stresses. vol. 1. Chilling, freezing, and high temperature stresses. Academic, New York. p. 197-227.

Li, J.C.R. 1964. Statistical inference I. Edwards Bros., Ann Arbor, Mich. p. 279-349.

McEvoy, F.A. and W.S. Lynn. 1972. The effects of temperature on photophosphorylation and on 
the two forms of cytochrome 559 in subchloroplast particles. Archs. Biochim. Biophys. 150:632-635.

Sink, K.C. and D.E. Walker. 1964. Effects of photoperiod and gibberellin on growth and flowering of azaleas. Proc. Amer. Soc. Hort. Sci. 84:564-569.

Steffen, K.L. and J.P. Palta. 1986. Effect of light on photosynthetic capacity during cold acclimation in a cold-sensitive and a cold-tolerant potato species. Physiol. Plantarum 66:353-359. Wintermans, J.F. and A. DeMots. 1965. Spectrophotometric characteristics of chlorophylls a and $\mathrm{b}$ and their pheophytins in ethanol. Biochim. Biophys. Acta 109:448-453. 